\title{
Influência da temperatura e das posições \\ na secagem de plantas medicinais em \\ um secador a base de energia solar
}

\author{
Influence of temperature and drying position of medicinal \\ plants in a dryer based on solar energy
}

Claus Isenberg ${ }^{[a]}$, Márcia de Holanda Nozaki[ ${ }^{[b]}$

[a] Engenheiro agrônomo graduado pela Pontifícia Universidade Católica do Paraná, câmpus Toledo, Toledo, PR - Brasil, e-mail: cl.isenberg@uol.com.br

[b] Professora Doutora da Pontifícia Universidade Católica do Paraná, câmpus Toledo, Toledo, PR - Brasil, e-mail: marcia.nozaki@pucpr.br

\section{Resumo}

As plantas medicinais têm criado uma grande demanda atualmente, possibilitando um nicho de mercado a ser explorado, gerando interesse de agricultores para esse novo tipo de cultivo. Entretanto, por se tratar de plantas para promoção da saúde humana, exigem tratamento diferenciado no seu cultivo e beneficiamento. Um desses tratos, se não o mais importante, é a secagem. Alguns cuidados devem ser tomados na secagem dessas plantas a fim de não comprometer o teor de princípios ativos ali presentes. Portanto, essa secagem irá depender muito do método utilizado. Dentre esses métodos, pode-se citar o artificial, que utiliza alguma fonte de calor para aquecimento do ar de secagem, sendo uma alternativa para essa fonte a energia solar, renovável e barata. Com base no exposto, o presente trabalho objetivou avaliar os efeitos da temperatura e as diferentes posições de secagem de três espécies de plantas medicinais em um secador a base de energia solar, objetivando menor perda dos princípios ativos do produto final. 0 delineamento experimental utilizado foi inteiramente casualizado. As espécies utilizadas no experimento foram: capim-limão, alfavaca e embaúba. Foram realizados dois ensaios diferentes, constituídos por: influência da temperatura na porcentagem de perda de massa fresca $\left(40^{\circ} \mathrm{C}\right.$ e $\left.50{ }^{\circ} \mathrm{C}\right)$ e influência da posição do material dentro do secador na porcentagem de perda da massa fresca (terço inferior, mediano e superior). Para tanto, foram realizadas avaliações da massa das plantas no momento de instalação do experimento e, posteriormente, as 42 e 90 horas após o processo de secagem. Os resultados mostraram que, para esse tipo de secador, as posições do terço inferior apresentaram perda de massa mais acentuada do que as posições superiores e que a temperatura de $40{ }^{\circ} \mathrm{C}$ mostrou-se mais eficiente na secagem de capim-limão e alfavaca.

Palavras-chave: Energia solar. Secador. Cymbopogon citratus. Ocimum basilicum. Cecropia hololeuca. 


\section{Abstract}

Medicinal plants has created a great demand in nowadays, creating a niche market to be exploited, generating interest of farmers to this new type of cultivation. However, since these plants promote human health, they require different treatment in its cultivation and processing. One such treatment, if not the most important is the drying. Care should be taken in the drying of these plants in order not to compromise the content of active ingredients present, so this will greatly depend on the drying method used. Among these methods, it can be mentioned the artificial method, which uses a heat source for heating the drying air, and an alternative source for this is solar energy, renewable and cheap. Based on the foregoing, the present study evaluated the effects of temperature and different drying positions of three species of medicinal plants in a drier based on solar energy to have less loss of active ingredients on the final product. The experiment was conduced in a complete randomized design. The species used in the experiment were: lemon grass, basil and embaúba. It was performed two different tests, consisting of: influence of temperature on the percentage of fresh weight loss $\left(40{ }^{\circ} \mathrm{C}\right.$ and $\left.50{ }^{\circ} \mathrm{C}\right)$ and influence of the position of the material inside the dryer in the percentage of fresh weight loss (inferior, middle and upper third). Thus, it was evaluated the mass of plants at the moment of instalation of the experiment, and subsequently, 42 and 90 hours after the drying process. The results showed that for this type of dryer, the positions of the lower third had a more pronounced weight loss than the top positions and the temperature of $40^{\circ} \mathrm{C}$ was more efficient in the drying of lemon grass and wild basil.

Keywords: Solar energy. Dryer. Cymbopogon citratus. Ocimum basilicum. Cecropia hololeuca.

\section{Introdução}

A utilização de plantas para a promoção da saúde humana tem sido difundida desde os primórdios da civilização. Contudo, após a Segunda Guerra Mundial muitos estudos foram direcionados para as drogas sintéticas, esquecendo-se assim do poder das plantas. Apesar disso, a partir dos anos 1980 foram retomados os estudos com essas plantas e seus constituintes (LAMEIRA et al., 2004).

Atualmente, o mercado de plantas medicinais e seus derivados mostra-se uma alternativa rentável aos pequenos agricultores, dada a grande procura por esse tipo de produto (CORRÊA Jr. et al., 2006). Essa demanda é gerada por uma população relativamente grande de países subdesenvolvidos que dependem dos produtos derivados dessas plantas, por se tratarem de produtos de custo menor em comparação com os industrialmente processados (BEVILAQUA et al., 2007).

A utilização das plantas pela população tem gerado certas divergências. A grande maioria das pessoas acredita que, graças à origem natural, o produto não seja nocivo à saúde, ideia essa errônea, visto que muitas dessas espécies apresentam substâncias tóxicas ao organismo e que, em doses elevadas, podem levar à morte (LORENZI, 2002).
Dentre as espécies de interesse da população encontra-se a alfavaca (Ocimum basilicum), uma erva aromática muito utilizada como tempero, principalmente na região Nordeste do Brasil (BLANK et al., 2004); o capim-limão (Cymbopogon citratus), planta da família Poacea, também muito explorado em função do seu óleo essencial para uso na indústria farmacêutica e de cosméticos; e a embaúba (Cecropia hololeuca), árvore nativa das regiões Sul e Sudeste com grande potencial no uso contra hipertensão (LORENZI, 2002).

0 teor de princípio ativo presente na planta depende de vários fatores, como solo, clima e até mesmo o processamento pós-colheita que é dado ao material. No que se trata ao processamento pós-colheita, o que mais interfere no teor e manutenção desse princípio ativo é a secagem (CORRÊA Jr. et al., 2006). Nesse processo é retirada a água livre presente nos tecidos vegetais, impedindo que ocorra degradação enzimática e mantendo, assim, a qualidade do material (MARTINS, 2000).

Apesar disso, devem-se observar alguns critérios para a realização dessa secagem, tais como: evitar temperaturas excessivas e efetuar a secagem ao abrigo do sol, pois algumas plantas, principalmente as aromáticas, possuem óleos essenciais em sua composição, compostos muito sensíveis a altas temperaturas e luminosidade (SIMÕES; SPITZER, 2004). 
Além disso, Silva et al. (1995) citam que existe aumento do potencial de secagem, a medida que há aumento da temperatura do ar, causado pela diminuição da umidade relativa do ar, levando à evaporação da água livre dentro das células. Esse ar aquecido deve entrar em contato com o material a ser desidratado para então poder efetuar a retirada dessa umidade. Isso vai depender da forma como é construída a unidade de secagem, onde o ar aquecido pode não chegar a todo o material de uma forma homogênea, causando desuniformidade no processo.

Com base nessas informações, o objetivo do presente trabalho foi avaliar a perda de massa fresca de capim-limão, alfavaca e embaúba, submetidas a diferentes temperaturas e diferentes posições dentro de um secador a base de energia solar.

\section{Materiais e métodos}

0 presente trabalho foi realizado durante o período de 2008 a 2009 e conduzido em uma propriedade agrícola com latossolo vermelho distrófico (EMBRAPA, 2006) a $25^{\circ} 03^{\prime} 32 " \mathrm{~S}$ e $53^{\circ} 50^{\prime} 10^{\prime \prime} \mathrm{O}$, localizada no município de Vera Cruz do Oeste, região oeste do Estado do Paraná. Com base na classificação climática de Köeppen, a região é classificada como de clima subtropical; temperatura média no mês mais frio inferior a $18{ }^{\circ} \mathrm{C}$ (mesotérmico) e temperatura média no mês mais quente acima de $22^{\circ} \mathrm{C}$, com verões quentes, geadas pouco frequentes e tendência de concentração das chuvas nos meses de verão, contudo sem estação seca definida (IAPAR, 2009).

A área de cultivo foi implantada há dois anos, possuindo área total de um hectare, onde são cultivadas várias espécies de plantas medicinais, aromáticas e condimentares.

0 delineamento experimental utilizado foi inteiramente casualizado, sendo constituído por dois ensaios, em que o primeiro avaliou duas diferentes temperaturas e o segundo, três posições do material vegetal dentro do secador. Para o primeiro ensaio, foram realizadas 30 repetições, enquanto para o segundo foram 10 repetições em cada tratamento.

Secador: o secador, localizado na área de estudo, é um protótipo do tipo container de circulação forçada de ar aquecido via energia solar (Figura 1). O sistema de circulação do ar é parcialmente fechado, havendo a entrada de ar ambiente quando necessário. Possui quatro carrinhos de dimensões $2,43 \times$ $1,6 \times 1 \mathrm{~m}$, dispostos dois na frente e mais dois atrás, cada um contendo 20 bandejas, totalizando 80 . As bandejas possuem as dimensões de 0,06 × 1,6 × $1 \mathrm{~m}$ com orifícios na base para circulação de ar por entre o material. As bandejas estão espaçadas em $40 \mathrm{~cm}$ entre si.

Por se tratar de um secador que utiliza energia solar, o funcionamento deste depende da intensidade luminosa que incide na sua cobertura. Fatores como céu encoberto por nuvens podem afetar o funcionamento do secador e o processo como um todo. 0 período das avaliações (janeiro a abril de 2009) foi escolhido com base em previsões meteorológicas de duas fontes diferentes (CPTEC/INPE, 2009; Canal do Tempo, 2009), que mostraram cinco ou mais dias com menos de $50 \%$ de probabilidade de chuva e dias ensolarados a parcialmente nublados.

A cobertura do secador é de acrílico, possui área de captação de energia solar de aproximadamente $10 \mathrm{~m}^{2}$ e o interior da câmara de aquecimento pintado de preto. 0 ar aquecido é então forçado para o interior da câmara de secagem, com auxílio de dois ventiladores, em uma abertura na parte inferior da divisória, entre a câmara de secagem e a câmara dos ventiladores. Essa abertura inferior está situada a 8 $\mathrm{cm}$ do piso, possuindo dimensões de $30 \mathrm{~cm}$ de altura por 2 metros de largura.

O secador possui um console onde se determina o valor da temperatura desejada de trabalho. Essa temperatura é monitorada por um sensor no interior da câmara de secagem. Quando o ar no interior dessa câmara atinge temperatura superior à estipulada no

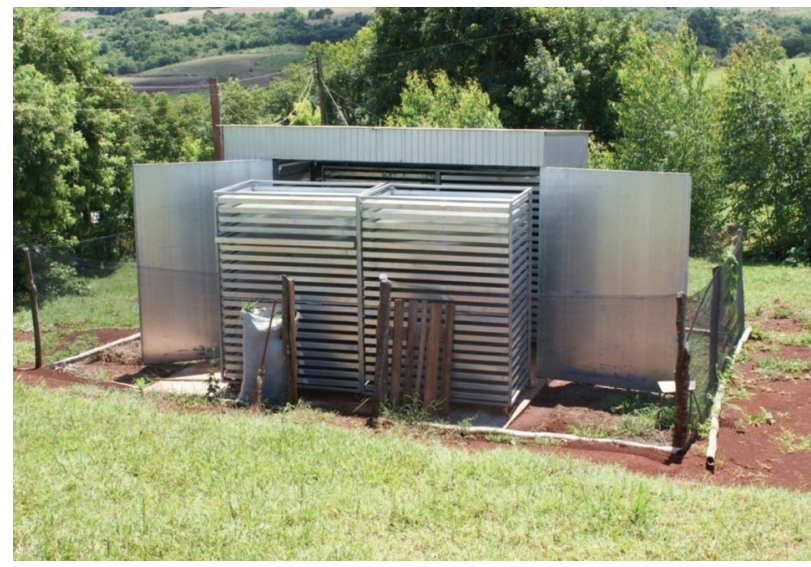

Figura 1 - Vista geral do secador à base de energia solar 
console, automaticamente abrem-se aletas para entrada de ar ambiente, mais frio que o do interior do secador. Nessa ocasião, abrem-se simultaneamente aletas para saída do ar úmido contido no interior da câmara de secagem.

Na parte superior da divisória, entre as câmaras de secagem e dos ventiladores, existem aletas de retorno, que fazem com que parte do ar contido dentro da câmara de secagem retorne à dos ventiladores, auxiliando na circulação do ar aquecido naquela região. Essas aletas possuem as dimensões de $30 \mathrm{~cm}$ de altura e $90 \mathrm{~cm}$ de largura, sendo compostas de duas aletas separadas $20 \mathrm{~cm}$ uma da outra. Durante o experimento, essas aletas foram mantidas com uma abertura de $3 \mathrm{~cm}$.

Aberturas situadas no retorno do ar para a câmara de aquecimento foram também reguladas, deixando apenas $4 \mathrm{~cm}$ para a passagem do ar. Essas aberturas possuem as mesmas dimensões das aletas anteriormente descritas.

Espécies avaliadas: as espécies utilizadas no experimento foram coletadas na propriedade agrícola de cultivo de plantas medicinais, aromáticas e condimentares. 0 capim-limão (Cymbopogon citratus) e a alfavaca (Ocimum basilicum) foram oriundos da área implantada, com dois anos de cultivo, enquanto a embaúba (Cecropia hololeuca), considerada planta nativa da região, foi coletada na própria área. Essas coletas foram realizadas com o auxílio de uma tesoura de poda e uma foice.

Previamente, houve um teste prévio para verificar qual a quantidade de material adequada a ser coletada e disponibilizada nas bandejas. Para as espécies estudadas foram utilizadas as folhas inteiras de embaúba, folhas de capim-limão com $30 \mathrm{~cm}$ de comprimento, e para alfavaca foram utilizados ramos de aproximadamente $20 \mathrm{~cm}$ de comprimento. Foram coletados 2,5 kg e 1,6 kg de limbos foliares de capim-limão e embaúba, respectivamente, enquanto para alfavaca foram coletados $2,5 \mathrm{~kg}$ de partes aéreas das plantas, por possuir folhas muito pequenas, dificultando assim o seu manejo. Essa variação de peso se deve ao volume ocupado muito maior apresentado por essa última planta.

A coleta dos materiais se deu a partir das $7 \mathrm{~h}$ da manhã por conta da maior concentração de óleo essencial encontrada nesse período para a alfavaca (SOARES et al., 2007), além de buscar aproveitar o aquecimento do secador pela energia solar ainda no mesmo dia.

Todo o trabalho de coleta dos materiais e deposição dentro do secador foi realizado antes das $12 \mathrm{~h}$ em ambos os ensaios realizados. As espécies foram submetidas aos tratamentos simultaneamente nos diferentes ensaios, sendo realizadas as avaliações em épocas distintas, conforme o ensaio realizado.

Ensaio 1 - Influência da temperatura na porcentagem de perda da massa fresca

Para esta avaliação, o material coletado foi submetido à desidratação, no secador anteriormente descrito, em duas temperaturas, $40{ }^{\circ} \mathrm{C}$ e $50{ }^{\circ} \mathrm{C}$. Os ventiladores foram ligados às $7 \mathrm{~h}$ e desligados às 20h, pois não havia a necessidade de deixá-los ligados durante a noite, em resposta ao seu funcionamento via energia solar.

Cada carrinho foi preenchido totalmente com uma das três espécies estudadas, sendo avaliadas apenas as cinco bandejas superiores, as cinco medianas e as cinco inferiores. 0 carrinho restante foi preenchido com capim-limão, apenas para simular uma situação real de secagem, em que todos os carrinhos do secador estão preenchidos com material vegetal, porém, não foi feita qualquer avaliação nesse último lote. Foram feitas duas secagens para cada temperatura, sendo estas realizadas aos sábados e às quartas-feiras, em função do pouco espaço disponível dentro do secador para efetuar as dez repetições ao mesmo tempo. As pesagens do material foram realizadas todos os dias antes do sol nascer, a fim de não interferir no aquecimento do secador. Essas pesagens foram realizadas com o auxílio de uma balança digital com precisão de $0,2 \mathrm{~kg}$.

Para a avaliação dos dados foram utilizados os valores obtidos na segunda e na quarta manhã de avaliação, o que correspondeu a 42 e 90 horas a partir do início do processo de secagem. Estudos prévios realizados antes das avaliações definitivas, nesse mesmo secador e com as mesmas espécies, mostraram que o término da secagem seria de aproximadamente 96 horas. 0 valor de 90 horas foi escolhido por se situar próximo ao do término do processo. 0 valor de 42 horas foi apenas um intermediário nesse tempo para melhor avaliação no transcorrer da secagem. 0 material foi mantido dentro do secador até que não 
houvesse mais alteração de peso entre um dia e outro, sendo esse o critério para o término da avaliação.

Ensaio 2 - Influência da posição do material dentro do secador na porcentagem de perda da massa fresca

Nessa avaliação, o material coletado foi disposto em três posições diferentes dentro do secador, sendo terço superior, terço mediano e terço inferior. 0 restante das bandejas foi preenchido com a espécie correspondente, para simular uma situação real de secagem.

Essa avaliação foi realizada simultaneamente com a anteriormente descrita. A metodologia utilizada foi semelhante, diferindo apenas na temperatura de secagem que foi de $40{ }^{\circ} \mathrm{C}$. Segundo Soares et al. (2007), essa temperatura apresenta os maiores rendimentos de óleo essencial para alfavaca.

Os dados coletados todos os dias foram expostos em gráficos da evolução da porcentagem de massa com relação à fresca.

Análise de dados: inicialmente foi feita a análise descritiva dos dados e a verificação da normalidade dos erros, seguida da análise de variância (ANOVA). A comparação das médias foi realizada pelo teste de Tukey ao nível de 5\% de significância (GOMES, 2000), no software Sisvar versão 5.1 (Build 72), desenvolvido pela Universidade Federal de Lavras (UFLA).

\section{Resultados e discussão}

\section{Ensaio 1 - Influência da temperatura na} porcentagem de perda da massa fresca

Para a alfavaca, não houve diferença significativa de porcentagem em relação à massa fresca a 42 horas do início do processo de secagem. Contúdo, foi apresentada menor perda de massa a $50{ }^{\circ} \mathrm{C}$ a 90 horas do início da secagem, diferindo significativamente do tratamento a $40{ }^{\circ} \mathrm{C}$ (Tabela 1). Enquanto, para o capim-limão, houve diferença significativa para as médias de massa em relação à massa fresca a 42 e a 90 horas do início da secagem.

As diferenças de pesos entre as avaliações podem ser atribuídas à evaporação da água livre presente nos tecidos das plantas (ROCHA et al., 2000). A menor perda de água em temperaturas mais elevadas, como no caso de alfavaca a 90h IPS e capim-limão a 42 horas e 90h IPS, pode ser possivelmente explicado pelo fato dos tecidos das plantas medicinais apresentarem-se tenros no momento da colheita. Ou, ainda, segundo Pillar (1995), essa resposta pode se dar graças ao fato de que a transpiração do material vegetal consome energia, portanto, resfria a folha e, consequentemente, pode haver menor perda de água, como apresentado no presente trabalho.

A abertura dos estômatos regula o fluxo de ar entre o interior da folha e a atmosfera, controlando a perda d'água. Os estômatos se fecham também em resposta a um déficit hídrico; a temperatura da folha tenderia a aumentar e, consequentemente, haveria perda de água. Entretanto, a murcha pode produzir uma modificação no ângulo de incidência da absorção da radiação solar, reduzindo-a. A transpiração aumenta diretamente com a magnitude da diferença de temperatura entre a superfície foliar e a camada adjacente de ar.

Tabela 1 - Diferença de porcentagem (\%) em relação à massa fresca a 42 horas do início do processo de secagem (42h IPS) e a 90 horas do início do processo de secagem (90h IPS) de alfavaca (Ocimum basilicum), capim-limão (Cymbopogon citratus) e embaúba (Cecropia hololeuca) a $40^{\circ} \mathrm{C}$ e $50^{\circ} \mathrm{C}$

\begin{tabular}{lccc}
\hline Espécie & $\begin{array}{c}\text { Temperatura de } \\
\left.\text { secagem ( }{ }^{\circ} \mathrm{C}\right)\end{array}$ & 42h IPS (\%) & 90h IPS (\%) \\
\hline Alfavaca & 40 & $52,78 \mathrm{~A}$ & $17,18 \mathrm{~b}^{*}$ \\
& 50 & $47,69 \mathrm{~A}$ & $18,73 \mathrm{a}$ \\
\hline \multirow{2}{*}{ Capim-limão } & $\mathrm{CV}(\%)=$ & 20,41 & 14,68 \\
& 40 & $43,99 \mathrm{~B}$ & $24,74 \mathrm{~b}^{*}$ \\
& 50 & $48,29 \mathrm{~A}$ & $27,49 \mathrm{a}$ \\
\hline \multirow{2}{*}{ Embaúba } & $\mathrm{CV}(\%)=$ & 11,43 & 3,43 \\
& 40 & $47,44 \mathrm{~A}$ & $36,78 \mathrm{a}$ \\
& 50 & $44,65 \mathrm{~A}$ & $36,75 \mathrm{a}$ \\
\hline & $\mathrm{CV}(\%)=$ & 12,94 & 9,74 \\
\hline
\end{tabular}

Legenda: * = médias seguidas da mesma letra na mesma coluna, para cada espécie, não diferem entre si pelo teste de Tukey a $5 \%$.

Fonte: Dados da pesquisa. 
Resultados semelhantes foram encontrados por Martins (2000) a $50{ }^{\circ} \mathrm{C}$. 0 autor constatou que o fato de o secador não dispor de sistema de controle da umidade relativa do ar de secagem, para que essa fosse mantida constante nos ensaios de mesma temperatura, pode ser considerado como a principal causa do aumento do tempo de secagem a $50{ }^{\circ} \mathrm{C}$.

Esses resultados divergem do encontrado por Silva et al. (1995), em que existe aumento do potencial de secagem em decorrência do aumento da temperatura do ar, ocasionando diminuição da umidade relativa do ar de secagem. Vale lembrar que variações na secagem podem ter sido induzidas por fatores climáticos, como chuva ou céu encoberto por nuvens.

E, por fim, a embaúba não apresentou diferença significativa na massa com relação à massa fresca tanto a 42 horas quanto a 90 horas do início da secagem, nas diferentes temperaturas avaliadas.

Dentre as espécies estudadas, a embaúba foi a que apresentou menor redução de sua massa se comparada com as demais espécies, enquanto a alfavaca foi a espécie que mais perdeu massa desde o início do processo de secagem, mostrando que essa última espécie provavelmente possui grandes quantidades de água em sua composição quando verde.

Rocha et al. (2000) encontraram valores de tempos até a estabilização do peso de aproximadamente 72 horas para a citronela (Cymbopogon winterianus) nas temperaturas de $40{ }^{\circ} \mathrm{C}$ e $50{ }^{\circ} \mathrm{C}$, valores esses muito próximos dos encontrados no presente trabalho. Essas diferenças entre os dois trabalhos podem ser atribuídas ao tipo de secador e às espécies utilizadas.

Ensaio 2 - Influência da posição do material dentro do secador na porcentagem de perda da massa fresca

Para cada espécie de planta foi elaborada uma curva com a evolução da perda da massa fresca conforme posição dentro do secador. Os resultados apresentados na Tabela 2 mostram que, para todas as espécies avaliadas, há perda maior de umidade do material na posição do terço inferior a 42 horas de secagem. Essa maior perda pode ser atribuída à forma como o secador foi construído, já que ele injeta o ar aquecido pela parte inferior da unidade, fazendo com que o material ali presente receba ar provavelmente mais seco e quente que o das demais posições.
Martins (2000) encontrou valores de tempo de secagem de capim-limão de aproximadamente cinco horas para a temperatura de $40^{\circ} \mathrm{C}$ e de duas horas e meia para a temperatura de $50{ }^{\circ} \mathrm{C}$ a uma velocidade do vento de $0,5 \mathrm{~m} \cdot \mathrm{s}^{-1}$. Esses resultados divergem dos encontrados no presente estudo. Essa divergência pode ser atribuída ao tipo do secador, que no presente estudo promovia o aquecimento do ar, dependendo exclusivamente da radiação solar variante no decorrer do dia, enquanto no experimento de Martins (2000) o aquecimento do ar era gerado por resistências elétricas que mantinham uma temperatura constante durante todo o processo.

Já para os valores de massa a 90 horas do início da secagem, observa-se a mesma tendência do início ao término do processo para a alfavaca, em que os valores de umidade são menores no terço inferior, seguido do terço mediano e superior (Gráfico 1).

Para o capim-limão também foi observada maior perda de umidade no terço inferior a 42 horas de

Tabela 2 - Diferença de porcentagem (\%) em relação à massa fresca a 42 horas do início do processo de secagem (42h IPS) e a 90 horas do início do processo de secagem (90h IPS) de alfavaca (Ocimum basilicum), capim-limão (Cymbopogon citratus) e embaúba (Cecropia hololeuca) em diferentes posições dentro do secador

\begin{tabular}{llcl}
\hline Espécie & Posição & 42h IPS (\%) & 90h IPS (\%) \\
\hline Alfavaca & Superior & $61,37 \mathrm{~A}$ & $19,20 \mathrm{a}^{*}$ \\
& Mediana & $49,46 \mathrm{~B}$ & $17,52 \mathrm{ab}$ \\
& Inferior & $39,86 \mathrm{C}$ & $17,15 \mathrm{~b}$ \\
\hline \multirow{2}{*}{ Capim-limão } & CV (\%) $=$ & 11,15 & 10,23 \\
& Superior & $51,91 \mathrm{~A}$ & $26,60 \mathrm{a}$ \\
& Mediana & $47,23 \mathrm{~B}$ & $25,72 \mathrm{~b}$ \\
& Inferior & $39,28 \mathrm{C}$ & $26,03 \mathrm{ab}$ \\
\hline \multirow{2}{*}{ Embaúba } & CV (\%) $=$ & 16,05 & 14,91 \\
& Superior & $50,00 \mathrm{~A}$ & $36,67 \mathrm{a}$ \\
& Mediana & $46,32 \mathrm{ab}$ & $37,50 \mathrm{a}$ \\
& Inferior & $41,83 \mathrm{~B}$ & $36,13 \mathrm{a}$ \\
\hline & CV (\%) $=$ & 11,77 & 16,65 \\
\hline
\end{tabular}

Legenda: ${ }^{*}$ = médias seguidas da mesma letra na mesma coluna, para cada espécie, não diferem entre si pelo teste de Tukey a $5 \%$.

Fonte: Dados da pesquisa. 


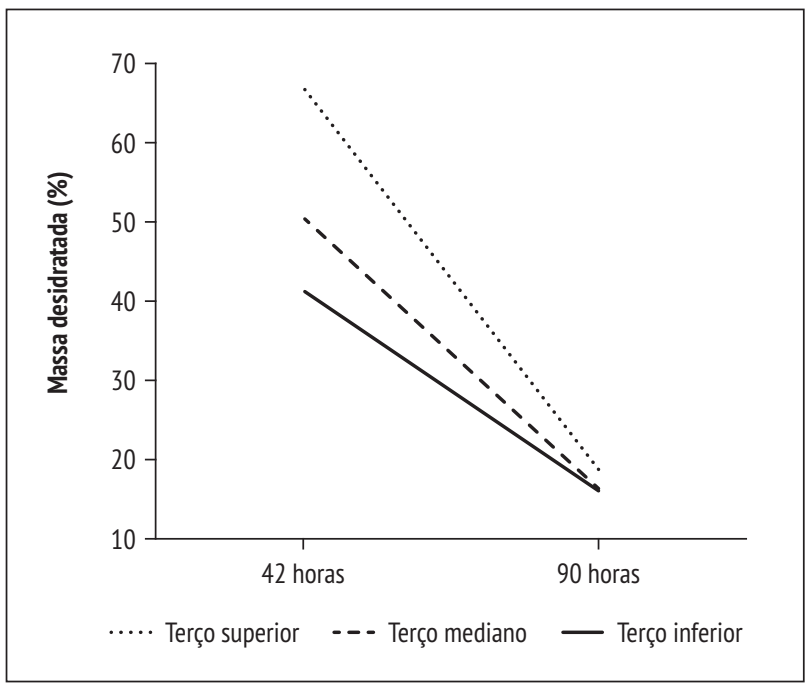

Gráfico 1 - Curva de evolução da porcentagem (\%) de massa parcialmente desidratada de alfavaca (Ociumum basilicum)

Fonte: Dados da pesquisa.

secagem. Já ao final da avaliação, o menor valor de massa foi observado no terço mediano, porém, não diferindo estatisticamente dos valores encontrados para o terço inferior. 0 Gráfico 2 mostra a evolução da perda de umidade no material.

Em experimento realizado por Martins (2000), mostra-se que o capim-limão apresentou rápida perda de umidade já nas primeiras horas a partir do início do processo de desidratação, diminuindo gradativamente ao longo do tempo. Resultado esse muito semelhante ao apresentado no Gráfico 2.

Para a embaúba também foi observada maior perda de umidade no terço inferior a 42 horas de secagem. Já ao final da avaliação, o menor valor de massa foi observado no terço mediano, porém, não diferindo estatisticamente dos valores encontrados para o terço inferior (Gráfico 3).

Esses valores mais elevados de massa no terço superior em todas as espécies estudadas podem ter sido influenciados pela abertura muito restrita do retorno do ar aos ventiladores, fazendo com que houvesse circulação insuficiente de ar aquecido naquele local, prejudicando assim a perda de umidade. Contudo, novos estudos são necessários para confirmar essa hipótese. Em resumo, de acordo com os gráficos apresentados, pode-se observar que a embaúba apresentou secagem mais rápida que o capim-limão, seguido da alfavaca.

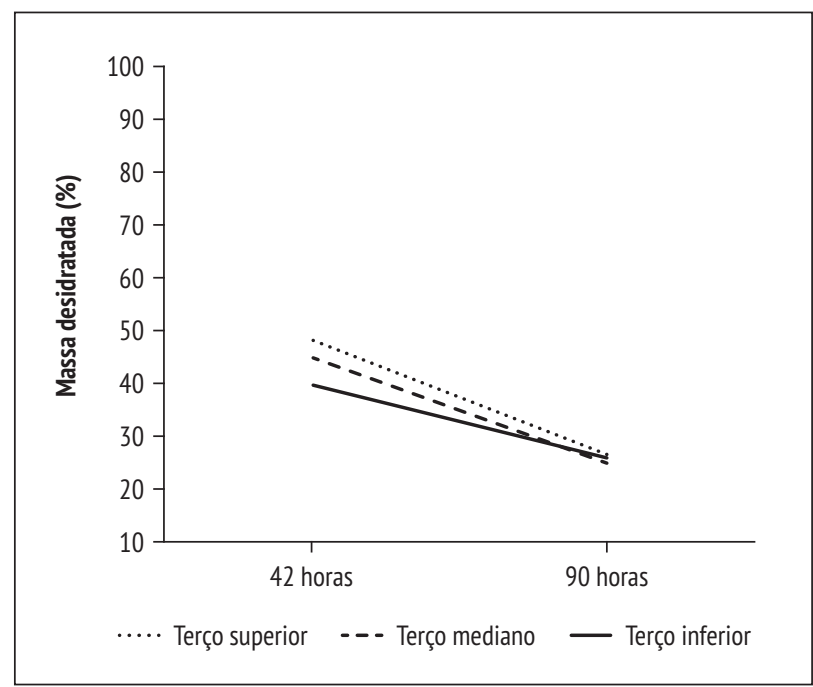

Gráfico 2 - Curva de evolução da porcentagem (\%) de massa parcialmente desidratada de capim-limão (Cymbopogon citratus)

Fonte: Dados da pesquisa.

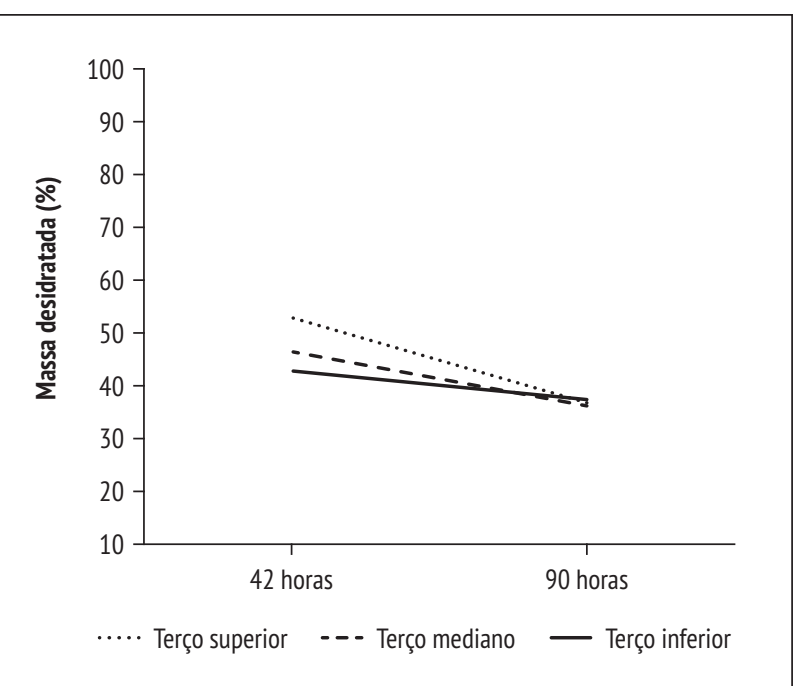

Gráfico 3 - Curva de evolução da porcentagem (\%) de massa parcialmente desidratada de embaúba (Cecropia hololeuca)

Fonte: Dados da pesquisa.

\section{Conclusão}

O capim-limão e a alfavaca apresentaram menores valores de perda de massa fresca a uma temperatura de secagem de $40{ }^{\circ} \mathrm{C}$. Para a embaúba, não foi apresentada diferença de massa entre as temperaturas de secagem estudadas, nos dois horários de 
coleta dos dados. Graças ao tipo de secador, as plantas do terço inferior tiveram perda de umidade mais acentuada que as demais posições de secagem.

\section{Agradecimentos}

À Sustentec e seus colaboradores: Euclides Lara Cardozo Júnior, Paulo Cezar do Amaral Júnior, Glaucia Bravo Dias e demais integrantes, por propiciarem a oportunidade de trabalhar com os agricultores no cultivo de plantas medicinais, aromáticas e condimentares.

\section{Referências}

BEVILAQUA, G. A. P. et al. Identificação e tecnologia de plantas medicinais da flora de clima temperado. Pelotas: Embrapa, 2007. p. 29. (Circular Técnica, n. 61).

BLANK, A. F. et al. Caracterização morfológica e agronômica de acessos de manjericão e alfavaca. Horticultura Brasileira, v. 22, n. 1, p. 113-116, 2004.

CANAL DO TEMPO. Previsão do tempo para região de Toledo, PR. Disponível em: <http://br.weather.com/weather/local/BRXX3706? $\mathrm{x}=0 \& \mathrm{y}=0>$. Acesso em: 10-18 fev. 2009, 5 mar. 2009 e 5-8 abr. 2009.

CENTRO DE PREVISÃO DE TEMPO E ESTUDOS CLIMÁTICOS - CPTEC/INPE. Previsão numérica, modelos regionais, Eta20, região de Cascavel, PR. Centro de previsão de tempo e estudos climáticos. Disponível em: <http:// previsaonumerica.cptec.inpe.br/>. Acesso em: 10-18 fev. 2009, 5 mar. 2009 e 5-8 abr. 2009.

CORRÊA Jr., C. et al. Cultivo agroecológico de plantas medicinais, aromáticas e condimentares. Brasília: Ministério do Desenvolvimento Agrário, 2006.

EMPRESA BRASILEIRA DE PESQUISA AGROPECUÁRIA EMBRAPA. Sistema brasileiro de classificação de solos. Brasília: Embrapa/CNPS, 2006.

GOMES, F. P. Curso de estatística experimental. 14. ed. Piracicaba: Pegaspari, 2000.
INSTITUTO AGRONÔMICO DO PARANÁ - IAPAR. Classificação climática do Estado do Paraná. Disponível em: <http://www.iapar.br/modules/conteudo/conteudo. php?conteudo=863>. Acesso em: 12 ago. 2009.

LAMEIRA, O. A. et al. Plantas medicinais: usos e manipulação. Belém: Embrapa, 2004. Comunicado Técnico.

LORENZI, H. Plantas medicinais no Brasil: nativas e exóticas. Nova Odessa: Instituto Plantarum, 2002.

MARTINS, P. M. Influência da temperatura e da velocidade do ar de secagem no teor e na composição química do óleo essencial de capim-limão (Cymbopogon citratus (D.C.) STAPF). 2000. 91 f. Tese (Mestrado em Engenharia Agrícola) - Universidade Federal de Viçosa, Viçosa, 2000.

PILLAR, V. D. Clima e vegetação. 1995. Disponível em: <http://ecoqua.ecologia.ufrgs.br>. Acesso em: 8 abr. 2009.

ROCHA, S. F. R. et al. Influência de cinco temperaturas de secagem no rendimento e composição do óleo essencial de citronela (Cymbopogon winterianuns Jowitt). Revista Brasileira de Plantas Medicinais, v. 3, n. 1, p. 73-78, 2000.

SILVA, J. S. et al. Estudos dos métodos de secagem. In: SILVA, J. de S. Pré-processamento de produtos agrícolas. Juiz de Fora: Instituto Maria, 1995. p. 105-143.

SIMÕES, C. M. O.; SPITZER, V. Óleos voláteis. In: SIMÕES, C. M. O. et al. Farmacognosia: da planta ao medicamento. 5. ed. Porto Alegre; Florianópolis: Ed. da UFRGS; Ed. da UFSC, 2004. p. 467-495.

SOARES, R. D. et al. Influência da temperatura e velocidade do ar na secagem de manjericão (Ocimum basilicum L.) com relação aos teores de óleos essenciais e de linalol. Ciência e Agrotecnologia, v. 31, n. 4, p. 1108-1113, 2007.

Recebido: 01/08/2010 Received: 08/01/2010

Aprovado: 01/09/2010 Approved: 09/01/2010 